\title{
MY TROUBLE IS MY ENGLISH: ASIAN STUDENTS AND AMERICAN DREAM
}

Eliete Sampaio Farneda*

\section{RESENHA}

FU, Danling (1995). My Trouble is my English: Asian Students and the American dream. Portsmouth/NH: Heinemann.

Publicada em 1995, a obra My trouble is my English: Asian Students and the American dream, aborda de modo abrangente o ensino de uma língua estrangeira para falantes de outras línguas e a aplicação da análise sócio-pragmática em seus estudos.

A autora é licenciada em Linguística, Mestre em Literatura Americana e Doutora em Educação. Sua experiência de ensino em diferentes escolas de países diversos, proprocionou-lhe um sólido conhecimento na área de ensino/aprendizagem. Danling Fu cresceu na China Comunista, passou pela Revolução Cultural quando era adolescente, época em que as escolas foram fechadas. Recebeu uma bolsa de estudos e mudou-se para os Estados Unidos já adulta.

Seu livro relata sua experiência como professora de língua estrangeira, seus estudos e observações sobre o desenvolvimento de quatro estudantes Laotianos. Durante seus relatos, ela faz considerações a respeito das expectativas, frustrações e decepções ao estudar nos Estados Unidos e o despreparo dos professores e tutores, motivos que a levaram à observação e pesquisa sobre o ensino/aprendizagem de língua estrangeira.

Fu descreve sua paixão pela literatura, a maneira singular e mágica de interpretar as histórias, que despertou em outros um desejo de ler as mesmas histórias lidas por ela. Ela afirma que se educou através dos livros e descreve o tipo de literatura lida quando era adolescente e trabalhava em uma fazenda, como a tradução das literaturas russa, alemã, francesa, inglesa e espanhola.

O livro está organizado em Introdução, seis Capítulos e Conclusão. Na Introdução, Danling $\mathrm{Fu}$ apresenta sua formação na China e nos Estados Unidos abordando aspectos de sua experiência como professora de língua estrangeira. A autora se reporta a 1985, quando recebeu a oportunidade de cursar o Mestrado nos Estados

\footnotetext{
Mestre em Filologia e Língua Portuguesa pela Faculdade de Filosofia Letras e Ciências Humanas da Universidade de São Paulo e Professora de Português para falantes de outras línguas da Virginia Commonwealth University, USA.
} 
Unidos e discorre sobre suas frustrações na América em relação aos estudos, particularmente no modo de interpretar textos. Cita que os textos não eram interpretados com significados relevantes para a vida. Apenas os aspectos de "forma e estrutura" eram mencionados. Na América, a interpretação de texto era feita sem valorizar personagens e/ou lugares, diferente de sua maneira de interpretar os textos literários - ligando a leitura e a escrita a sua vida, buscando sua própria voz.

A pesquisadora mostra-se frustrada e insatisfeita, porque havia lido muitos gêneros literários durante o seu Mestrado na América, porém só conseguia lembrar-se dos livros lidos em sua adolescência, quando trabalhava na fazenda, na China. Seguiu seus estudos no Doutorado e percebeu que as aulas de leitura e escrita em língua estrangeira eram diferentes de todas as que ela havia participado. Os alunos podiam dar sentido ao texto de acordo com suas experiências de vida, podiam trazer o texto para a vida real e fazer a aprendizagem mais significativa. Conheceu os recursos da análise sócio-pragmática aplicada aos textos literários e acompanhou o desenvolvimento de quatro irmãos Laotianos (Tran,19; Cham, 17; Paw, 16; Sy, 14), estudantes de uma escola secundária nos Estados Unidos, no aprendizado do Inglês.

Danling mostra que o processo de aquisição e aprendizagem de uma língua estrangeira exige mais do que a presença de alunos e material didático em sala de aula. É um processo que vai além da sala de aula. Ela pesquisou os métodos utilizados pelos professores em diferentes salas de aula, entrevistando-os e armazenando dados sobre como eles se sentiam a respeito de seus trabalhos e a respeito de seus alunos. Além de entrevistar os professores, a pesquisadora também visitava a casa dos alunos, para conhecer sua realidade.

No capítulo inicial, trata da coleta de dados referentes a história da família Savang. A autora escreve o testemunho da de cada pessoa da família sobre seus sentimentos, sonhos deixados no Laos, seus medos e inseguranças. Fornece informações básicas sobre os quatro irmãos: sua família e da vida em seu país de origem, no campo de refugiados, e nos Estados Unidos.

Ela estudou suas atitudes, suas personalidades, a memória discursiva de cada um e sua adaptação nos Estados Unidos. Conversou com cada um dos irmãos sobre seus sentimentos pelos pais e pelo seu país de origem, suas esperanças no futuro. Todos esses dados contribuíram para que ela formulasse hipóteses a serem utilizadas na metodologia de ensino de língua estrangeira.

No segundo capítulo, a autora escreve sobre a vida escolar de cada um dos quatro estudantes. Neste capítulo, ela explica que os alunos não querem esquecer quem são, mas eles tentam encontrar uma maneira de sobreviver. Expressam seus desejos com e frases, como: "I don't understand what they say. I wish I could just do like them" (Cham); "I wish I could do everything like them - talk, laugh, and act, just everything, but I don't know how." (Sy); "I don't like to be like them. I just want to be myself" (Paw).

Danling descreve que o pensamento "para ter sucesso na América, tem de ter sucesso na escola", é uma preocupação constante na vida de cada um dos irmãos. Ela se concentra sobre os aspectos de interação entre professor / aluno e a marginalização decorrente desta falta de interação, o que consequentemente podem levar à falta de identidade cultural. 
Durante os três anos de estudo na América, os alunos do Laos não se sentiam parte da escola, porque o seu Inglês era muito diferente, causando o isolamento dos quatro irmãos. Isso aconteceu, em primeiro lugar, em decorrência de a escola não ponderar sobre seu papel diante do mundo, enquanto responsável pela formação do sujeito, com finalidade social. Em segundo lugar, pela postura do professor de língua estrangeira não estar voltada para o processo de desenvolvimento da cidadania, isto é, para que os fenômenos culturais fossem trabalhados dentro de um contexto sóciohistórico, a fim de não se tornarem apenas um mecanismo alienante. A falta de valores culturais atribuídos pelos professores é um fator negativo para o processo de aprendizagem de lingua estrangeira. A autora cita autores, como Spindler \& Spindler (1987); Trueba (1988a); Tharp \& Gallimore (1989), que afirmam que as atividades escolares devem tornar-se instrumentos para consecução de objetivos culturais e expressão de valores culturais. Em terceiro lugar, pela interferência da língua materna no aprendizado da língua alvo.

Há uma reflexão crítica a respeito dos procedimentos utilizados no ensino de língua estrangeira apoiada na visão de Austin (1986), de que o estudante não deve aprender uma língua apenas para saber o que dizer, mas como, onde, para quem e em que circunstâncias dizer. A autora descreve a preocupação dos alunos em estudar para ter sucesso nos testes, o que, segundo Smith (1986), pode provocar frustrações incorrendo no abandono escolar.

Do capítulo três ao seis, há uma descrição cronológica da análise do trabalho de leitura e escrita de cada aluno. Cada diálogo com o professor ou tutor, cada tipo de texto

produzido pelos alunos, foram documentados neste livro e analisados de forma substancial. As análises mostram o progresso de cada um, levando em consideração todos os tipos de produção, mesmo os desenhos feitos por Cham, a fim de expor suas idéias e sua cultura.

A autora enfatiza o processo de aprendizagem de uma língua estrangeira, neste caso o Inglês, e entende como pontos de conflito: a incapacidade de expressão dos estudantes para falar sobre suas experiências, trocar idéias e, a mecânica da incorporação do vocabulário e ortografia.

Danling exemplifica uma aula em que o professor faz algumas perguntas para Cham e ele não pode responder, porque não tem vocabulário suficiente para discutir o que foi solicitado para ele. A autora corrobora com Vygotsky (1986), que cita que a aprendizagem ocorre quando os estudantes têm o domínio de certas áreas do conhecimento. Ler e escrever sobre o que já é conhecido, é muito mais produtivo. Devido as suas observações, ela descreve o trabalho de alguns professores e tutores como improdutivo, ultrapassado, restrito às exigências do currículo. Afirma que os estudantes devem ter mais oportunidade de interagir com os colegas e os professores devem conhecer os seus alunos, a fim de evitar estereótipos culturais e marginalização. $\mathrm{O}$ professor deve ter a liberdade de trabalhar com abordagens multiculturais $\mathrm{e}$ inclusivas, para que os alunos sintam-se bem vindos e não apenas um estrangeiro dentro da sala de aula.

Danling prioriza o desenvolvimento de três competências: ouvir, compreender e falar. A escola, por sua vez, prioriza as competências: leitura, escrita. Isto fica 
esclarecido pelo fato de os professores entrevistados e analisados ensinarem a leitura e a escrita em maior grau que a leitura e contextualização através da interação dos alunos.

Ela enfatiza, através de suas pesquisas e observações, a falta de preparação do professor de língua estrangeira, talvez pela não existência de recursos educacionais, estratégias e objetivos claros voltados ao ensino de língua estrangeira para falantes de outras línguas. Sua experiência permite-lhe fazer algumas observações sobre a reformulação dos materiais didáticos, com textos e estratégias mais ligados ao presente, incluindo todos os alunos no processo ensino / aprendizagem. Ela sugere que haja uma reformulação nos cursos de formação para professores de língua estrangeira, para que o ensino não esteja focado somente em forma e estrutura, mas em uma abordagem sóciopragmática que situa o estudante como parte da nova cultura, sem que ele perca sua identidade e/ou passe pelo processo de marginalização e isolamento.

Assim, a autora conclui sua obra fornecendo subsídios necessários aos estudos voltados ao ensino/aprendizagem de língua estrangeira por falantes de outras línguas, à medida que trata da observação dos métodos utilizados, reportando-se a teóricos sempre que necessário. Os dados selecionados e estudados, nos permitem analisar teorias e reavaliar nossa metodologia de trabalho com estudantes estereotipados pela dificuldade em uma língua estrangeira. As abordagens nos auxiliam a pensar em novas estratégias de ensino, que motivem o aluno ao processo de aprendizagem.

Este livro constitui-se numa obra ainda pouco conhecida no Brasil, sem tradução em língua portuguesa. Embora date de 1995, a exemplificação de experiências e uso de determinadas metodologias podem suscitar estudos concernentes às dificuldades no aprendizado de uma língua estrangeira, por falantes de outras línguas, decorrentes da falta de metodologia adequada que inclua os valores culturais do aluno, no aprendizado da língua e da cultura estrangeira. 